\title{
Photoprotective Effects of Hydroalcohol Tagetes Erectus Extract Against UV-Induced Oxidative Damage in Mice
}

\author{
Monika Sachdeva $^{1^{\star}}$, Murli Dhar Kharya ${ }^{2}$, Ahmed Aljarbou ${ }^{3}$ and Taruna \\ Katyal $^{4}$ \\ ${ }^{1}$ College of Pharmacy, Qassim University, Buraidah, Saudi Arabia , ${ }^{2}$ Department of Pharmaceutical Sciences, Dr. H.S \\ Gour University, Sagar, M.P., India, ${ }^{3}$ College of Pharmacy, Qassim University, Buraidah, Saudi Arabia, ${ }^{4}$ I.S.F. \\ College of Pharmacy, Moga, Panjab, India.
}

\begin{abstract}
Purpose: To investigate the effects of topical application of Tagetes erectus hydroalcohol extract as a dermal antioxidant agent and evaluate its capacity to prevent ultraviolet (UV) -induced oxidative damage.

Methods: The plant flower was extracted with aqueous ethanol (60\%). Female Lacca mice were divided into five groups of 24 animals each. Group I was un-irradiated control (neither UV exposure nor any treatment received). Group II was irradiated control and received 5 min UV exposure twice a day. Groups III, $1 \mathrm{~V}$ and $V$ received both UV exposure and treatment of different concentrations of the extract, $4 \mathrm{~h}$. prior to UV exposure. The degree of protection was quantified using biochemical tests (lipid peroxidation and glutathione level) and histopathological assessment.

Results: The results showed that $2 \%$ topical extract treatment reduced the effect of UV light-induced photoaging on mice skin by decreasing malondialdehyde (MDA) level by up to $50 \%$ and increasing glutathione $(G S H)$ level 3-fold $(p<0.01)$ compared to UV-irradiated control group. Histopathological evaluation also indicated a photo-protective effect on the extract-treated mice skin as no signs of histological changes were seen after UV exposure.
\end{abstract}

Conclusion: Topical application of $T$.erectus has a potential for preventing oxidative damage by UV irradiation.

Keywords: T.erectus, Photo-ageing, skin wrinkles, Antioxidants, Oxidative damage, UV radiation 


\section{INTRODUCTION}

Skin aging is a complex biological process which is influenced by the interaction of several intrinsic and extrinsic factors. Intrinsic or chronological aging is an inevitable, genetically programmed process of unclear underlying mechanism, for which no prevention or effective treatment is available [1]. Photo-aging refers to the gross and microscopic cutaneous changes that are induced by cumulative exposure to UV radiation and are superimposed on the background of chronological ageing [2]. .The cellular effects of UV exposure are implicated in cutaneous ageing [3]. UV radiations induce structural and cellular changes in all compartments of skin [4]. The dermatologic importance of photoaging lies in the considerable cosmetic and psychosocial distress it causes older persons and in its strong, presumably etiological relationship to skin cancer [5]. Cutaneous sun exposure is perhaps the best documented and best researched example of environmental agents that accelerates intrinsic ageing processes in one or more organ systems [6].

The physical appearance of aged skin is due partly to UV exposure from the sun, resulting in noticeable textural, vascular and pigmentary skin changes in the form of fine and coarse wrinkles and keratoses [7]. In order to combat various deleterious effects produced by free radicals generated from ultraviolet radiation, the human body has developed some endogenous built-in antioxidant mechanisms. However unfortunately, these defense mechanisms may at times fail due to overwhelming production of toxic free radicals [8].

The use of topical antioxidants may be an effective strategy for counteracting the deleterious effects of UV-induce free radicals [9]. In the past decade ,the antioxidant activity of various plant phenolic, flavanoids, carotenoids, catechins, polyphenolic compounds and plant extracts have demonstrated the ability to suppress UV induced adverse effects [10].
Tagetes erectus (Compositae), commonly known as African marigold, is a stout perennial herbaceous $60 \mathrm{~cm}$ tall plant comprising of strongily scented,pinnately dissected oblong or lanceolate serrate leaves and solitary, yellow to orange ,5-10 $\mathrm{cm}$ across long clawed many rays flowers. The flower contains pigments such as quercetagetin and quercetagetrin [11-12]. .The flower heads of this herb is also rich in carotenoids copmpounds. This plant is used in traditional system of medicine as analgesic, anti-inflammatory and antioxidant agents due to its carotenoid consitutents[13,14,15].

Carotenoids compounds have been shown to act as potent anti-oxidants that believe to function by quenching free radicals and reactive oxygen species [16]. A survey of available literature on this plant revealed that despite being a excellent source of antioxidants constituents no scientific reports on topical anti-oxidant efficacy against UV irradiation adverse effects has been screened so far. For this reason, we investigated the potential ability of $T$. erectus flower extracts to mitigate UV-induced oxidative stress in mice skin.

\section{EXPERIMENTAL}

\section{Collection and identification of plant material}

Flowers of Tagetes erectus were purchased from the local market in the month of October-November. The plant material was authenticated by Professor MD Kharya on the basis of taxonomic characters and by direct comparison with the herbarium specimens available at the Museum/herbarium of Botany , Dr. Hari Singh Gour University, Sagar, MP, India. A voucher specimen (no. VD-2002- 10) was deposited at the herbarium of the Department of Botany, Dr. Hari Singh Gour University, Sagar, MP, India. 


\section{Preparation of plant extract}

The plant material was cleaned by dusting, sifting and blowing to remove surface contaminants. The flower heads were spread in layers over clean polythene sheets in an airy room and frequently turned over to facilitate drying and thus avoid any microbial growth. After drying, the material was grounded in a blender and sieved through a 40-mesh sieve to obtain a coarse powder.

The extract was prepared by maceration using $60 \%$ ethanol followed by Soxhlet extraction. $1200 \mathrm{~g}$ dried flower powder was homogenized with $60 \%$ ethanol $(2 \mathrm{~L})$. Homogenization was carried out for 7 days subsequently. The solvent used for maceration was re-cycled for extraction and this was continued until the material was exhausted. The extract was then concentrated to obtain a syrupy extract, which was then dried in a lyophilizer to obtain a yield of $170 \mathrm{~g}$ dry extract. Separately, 400, 600 and $800 \mathrm{mg}$ of lyophilized T. erectus extract was added in $20 \mathrm{ml}$ distilled water by gentle heat and thorough shaking to prepare $2 \%, 3 \%$ and $4 \%$ respectively.

\section{Selection of animals}

Female Lacca mice, weighing 15-25 g, were used. The Animal Ethical Committee of Dr. Hari Singh Gour University, Sagar, M.P, India approved the experimental protocols based on the guidelines of Committee for the Purpose of Control and Supervision of Experimental Animals, New Delhi, India (approval reg no. 397/01/ab/CPCSEA) . The animals were housed in plastic bottom cages where they were allowed free access to standard animal feed and water.

The hair on demarcated areas of approximately $4 \mathrm{~cm}^{2}$ on the dorsal surface of each mouse was removed using a Rose Anne French hair- removing cream. The mice were observed for $48 \mathrm{~h}$ and those showing any abnormal hair growth or any reaction to the cream were excluded. Hair removing cream was preferred to shaving blade in order to minimize free radical production due to trauma from the blade.

\section{UV light exposure conditions and development of photo-ageing}

The mice were divided into 5 groups of 24 animals each. Group I served as control. Group II animals received 5 min UV exposure twice a day and served as irradiated control. The test groups III, IV and $\mathrm{V}$ received both UV radiations and 2, 3 and $4 \%$ plant extract treatment, respectively. The treatment was given $4 \mathrm{~h}$ prior to UV exposure as per the protocol. All the animals were kept inside a solar simulator (designed in the laboratory and fitted with UV lamp) at a distance of 40 $\mathrm{cm}$ from the UV light source (Ultra Vitalux 300 W Waton $\AA$ bulb, Germany). The bulb gave the full spectrum of UV radiation, i.e., 260 - $400 \mathrm{~nm}$, simulating the full solar spectrum. UV exposure was controlled by time of exposure. Exposures were given twice daily for $5 \mathrm{~min}$. For the mice receiving topical extract treatment, the dorsal skin was treated with extract $4 \mathrm{~h}$ prior to each UV radiation exposure. The extract was delivered at a dose of $10 \mu \mathrm{l} / \mathrm{cm}^{2}$ area of the skin with micropipette. The animals were treated for 3 , 7, 11 and 15 days following which the skin was excised and preserved in a chilled sachet.

For histopathological investigation, the animals were treated for 30 days following which the skin was excised and used for histopathological studies.

\section{Biochemical determinations}

\section{Lipid peroxidation assay}

Lipid peroxidation was assessed in all groups by estimating 2-thiobarbituric acid reacting substance, i.e., malondialdehyde (MDA) [17]. To $0.2 \mathrm{ml}$ sample, $0.2 \mathrm{~mL}$ of $8.1 \%$ sodium lauryl sulphate and $1.5 \mathrm{ml}$ of $20 \%$ acetic acid solution ( $\mathrm{pH}$ adjusted to 3.5 with sodium hydroxide) were added. Then $1.5 \mathrm{ml}$ of $0.8 \%$ 
aqueous solution of thiobarbituric acid (TBA) was added. The mixture was made up to 40 $\mathrm{mL}$ with distilled water and heated in a water bath at $95^{\circ} \mathrm{C}$ for $60 \mathrm{~min}$. In cooling water 1.0 $\mathrm{ml}$ of distilled water and $5.0 \mathrm{ml}$ mixture of $\mathrm{n}$ butanol and pyridine $(15: 1 \mathrm{v} / \mathrm{v})$ were added. After centrifugation at $4000 \mathrm{rpm}$ for $10 \mathrm{~min}$. Absorbance of the organic layer was read at $532 \mathrm{~nm}$. The level of MDA was expressed as nmole per gm of tissue.

\section{Evaluation of glutathione (GSH)}

Glutathione either reduces $\mathrm{H}_{2} \mathrm{O}_{2}$ directly to water or reacts directly with free radicals such as $\mathrm{O}_{2}^{-{ }^{-}}, \mathrm{OH}^{-}, \mathrm{O}^{-1}$ by a radical transfer process to yield thiol radicals which form colored complexes with DTNB that absorb strongly at $412 \mathrm{~nm}[18]$.

After washing with saline, $500 \mathrm{mg}$ of skin tissue was homogenized with $5 \mathrm{ml}$ of $10 \%$ trichloroacetic acid (TCA) in a Teflon glass tissue homogenizer (Remi India). The homogenate was centrifuged at $3000 \mathrm{rpm}$ $\left(4^{\circ} \mathrm{C}\right)$ for $10 \mathrm{~min}$ and the supernatant fraction was diluted 10 fold with phosphate buffer .

In the glutathione assay, the reaction mixture contained $2 \mathrm{ml}$. Phosphate buffer in $100 \mathrm{ml}$ (PH 8.4), $100 \mu \mathrm{l}$ of sample and $500 \mu \mathrm{l}$ of $0.002 \%$ DTNB (2mg DTNB in $1 \%$ sodium citrate). To this reaction mixture, $400 \mu \mathrm{l}$ of distilled water was added and absorbance read at $412 \mathrm{~nm}$. GSH levels were expressed as $\mu \mathrm{g} / \mathrm{gm}$ of tissue.

\section{Histopathological studies}

Skin biopsies from dorsal portions of unirradiated control group, irradiated control group and UV-irradiated and treated groups were stored in $10 \%$ formalin, embedded in paraffin, and sectioned. The sections were then stained with aqueous haematoxylene and alcoholic eosin stain for routine examination of the tissues. Specific stains, namely, Verhoeff's and Van Gienson's, were used to check the status of elastic and collagen fibers, respectively. Elastic fibres were stained with Verhoff's stain to evaluate the area of the repair zone. Collagen fibres were stained with Van Gieson stain [19]. These sections were also analyzed for changes in integrity of vessels, inflammatory infiltrates, fibrosis and appearance of oedema.

\section{Statistical analysis}

The experimental results obtained were expressed as mean \pm standard error of mean (SEM). All measurements were carried out in triplicate. Means were compared for statistically significant differences by one-way analysis of variance (ANOVA) using Prism 4.03 (Graphic Pad Software, Inc, USA). Data were considered significantly different at $p<$ 0.05 .

\section{RESULTS}

The results for skin MDA level of the various groups are shown in Table 1. Treatment with the extract of three doses significantly reduced skin MDA levels of the irradiated mice after 11 days $(p<0.05)$. However, the reduction was not dose-dependent.

The esults for skin GSH level for the various groups are shown in Table 2. Treatment with three doses of the extract significantly increased skin GSH levels of the irradiated mice after 11 days $(p<0.05)$. However, it was noticed that three different doses of the extract did not show this activity in concentration-dependent manner. No significant difference between the three different doses was seen in the two biochemical assessments on any of the days during the treatment period $(p>0.05)$. As a result, only the $2 \%$ extract dose was screened for further histological studies.

Histopathological results for the irradiated control group (Fig 1a) showed a progressive damage to both epidermis and dermis at the end of 30 days. Deep lesions and alteration along with an overall oedema could also be seen in irradiated group. Furthermore, marked dermal fibrosis and elastosis were clearly indicated in UV-treated skin samples. 
In the extract-treated group (Figf 1b, no pronounced changes were observed in the epidermal region as well as in the connective tissue. No significant epidermal acanthosis was seen, and neither elastotic degeneration nor telangiectasis was visible in this group. Elastic fibres tended to be normal as appeared longer, thicker and less fragmented.
In UV-irradiated mice skin morphological changes in the form of deep lesions and ulcerations along with an overall erythema were observed. However, the treated mice skin indicated no sign of lesions and erythema.

Table 1: Levels of skin MDA in the irradiated, extract treated groups and controls

\section{Group}

\begin{tabular}{lllll}
\hline Un-irradiated control & $178.0 \pm 4.3$ & $180.0 \pm 3.3$ & $190.0 \pm 3.8$ & $213.0 \pm 5.3$ \\
Irradiated control & $315.0 \pm 13.1$ & $625.0 \pm 17.9$ & $753.0 \pm 14.4$ & $889.0 \pm 6.9$ \\
T. erectus (2\%) & $214.0 \pm 11.6$ & $454.0 \pm 11.3$ & $501.0 \pm 13.7^{*}$ & $498.0 \pm 5.6^{* *}$ \\
T. erectus (3\%) & $172.0 \pm 3.4$ & $407.0 \pm 21.3$ & $402.0 \pm 17.0^{*}$ & $471.0 \pm 13.8^{*}$ \\
$T$ T. erectus (4\%) & $172.0 \pm 3.2$ & $411.0 \pm 17.3$ & $405.0 \pm 12.6^{*}$ & $473.0 \pm 5.0^{*}$ \\
\hline
\end{tabular}

Values are expressed as mean \pm SEM $(n=6) ;{ }^{*} p<0.05 ;{ }^{* *} p<0.01$, compared to the irradiated control

\begin{tabular}{lcccc}
\hline \multirow{2}{*}{ Group } & \multicolumn{4}{c}{ Skin GSH $(\boldsymbol{\mu g} / \mathbf{g m})$} \\
\cline { 2 - 5 } & Day 3 & Day 7 & Day 11 & Day 15 \\
\hline Un-irradiated control & $282.0 \pm 5.2$ & $248.0 \pm 4.3$ & $233.0 \pm 2.8$ & $217.0 \pm 4.0$ \\
Irradiated control & $135.0 \pm 4.0$ & $125.0 \pm 4.8$ & $99.0 \pm 3.5$ & $66.0 \pm 3.8$ \\
$T$. erectus (2\%) & $211.0 \pm 6.2$ & $180.0 \pm 4.3$ & $172.0 \pm 7.1^{*}$ & $164.0 \pm 10.3^{* *}$ \\
T. erectus (3\%) & $247.0 \pm 6.4$ & $217.0 \pm 5.6$ & $216.0 \pm 5.6^{*}$ & $189.0 \pm 9.7^{*}$ \\
T. erectus (4\%) & $254.0 \pm 6.5$ & $224.0 \pm 4.9$ & $218.0 \pm 5.8^{*}$ & $192.0 \pm 9.7^{*}$ \\
\hline Values are expressed as mean $\pm S E M(n=6) ;{ }^{*} p<0.05 ;{ }^{* *} p<0.01$, compared to the irradiated control.
\end{tabular}

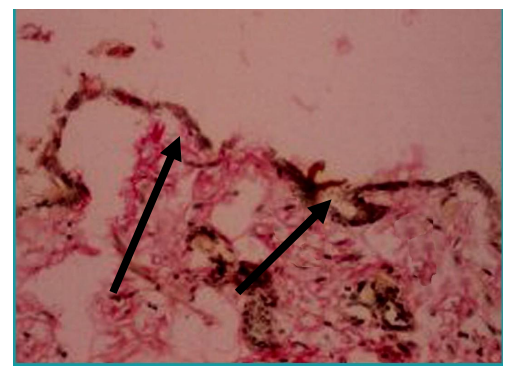

DL ELA

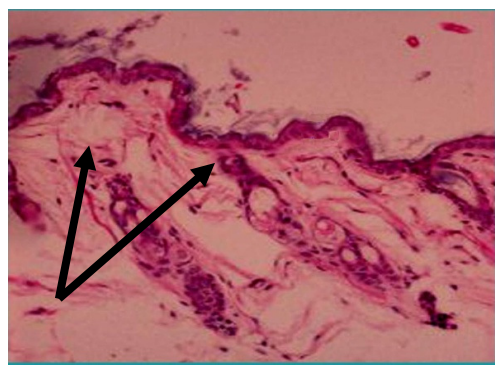

NCT

Fig 1: (a) Photomicrograph of UV-treated mice skin specimen (control) depicting deep lesions, oedema dermal fibrosis and elastosis (elastin fibres appear fragmented, short and curled, indicating severe photodamage ); H \& E stain; x 1000; (b) Photomicrograph of skin specimen from mice treated with $2 \% T$. erectus extract showing normal connective tissue without fibrosis and elastosis; elastin fibres appear longer, thicker and wavier (H \&E stain, x 1000). (Key: DL = deep esions; ELA = elstosis; NCT = normal connective tissue) 


\section{DISCUSSION}

Photoxidative damage caused by solar UV light is the leading cause of extrinsic ageing of the skin. Photoaging causes numerous histologic, physiologic and clinical changes [20]. Acute exposure of solar UV radiation on the skin induces oxidative stress, a major contributor to the process of photoaging of the skin [21]. Although cytoplasmic and mitochondrial defense mechanisms including the antioxidant enzymes glutathione peroxidase, glutathione reductase, superoxide dismutase and catalase have evolved to quench ROS, these antioxidant defense enzymes may become overwhelmed, and hence throughout life cells accumulate molecular evidence of oxidative damage [22]. Therefore new chemopreventive agents and strategies need to be developed to combat solar UV lightinduced oxidative damage, and oxidative damage-mediated photoaging. One of the approaches that have generated enormous interest is the use of naturally occurring antioxidants of plant origin. Diets rich in natural occurring polyphenols have been associated with photoprotective effects on skin due to their antioxidant activities.But another fact is that dietary supplementation of the antioxidants have limited cutaneous bioavailability and not thus sufficient to scavenge ROS generated in photoaged skin[23]. Consequently, there is great interest in using topical botanical supplements for the prevention of photoaging.

The results from the aforementioned biochemical studies suggest that $2 \% \quad T$. erectus extract could serve as a potential candidate against photo-oxidation and these finding were even more evident from the histologic data. A biopsy specimen from irradiated control mice group after 30 days of UV exposure, revealed marked elastosis with accumulation of elastotic material in the dermal layer while the biopsy specimen from extract-treated group revealed well-marked regular epidermal layers and collagen fibrils, comprising of reticular and elastic fibers. The reticular layer revealed bundles of collagen fibers. The effectiveness of T.erectus extract in preventing solar elastosis may be attributed to its polyphenolic constituents.

These compounds act in a photoprotective way as a filter of damaging blue light and also as antioxidants by neutralizing free radicals and reactive oxygen species responsible for cross-linking of collagen and elastin that leads to production of wrinkles. Based on this mechanism, the biochemical data for the extract-treated mice bolster are in consonance with the histologic finding of minimal photoaging damage (dermal elastosis and fibrosis) compared with mice treated with UV radiation only. The significant level of topical antioxidant activity of T.erectus extract could be attributed to the high amount of carotenoids in the extract. The result of this study indicates that T.erectus extract treatment helps to ameliorate and inhibit damage associated with photoaging of skin.

\section{CONCLUSION}

On the basis of biochemical and histopathological studies, it can be stated that $T$. erectus aqueous ethanol extract has antioxidant potentials against UV-induced oxidative stress and thus should be further evaluated as a natural photo-protective agent.

\section{REFERENCES}

1. Carletto C, Nicolay JF. Oxidative stress and cutaneous ageing: the toxic second messengers concept and an intresting family of products, pseudopeptides. Int $\mathrm{J}$ Cosmet Sci 2000; 22: 361-370.

2. Ansari KN. The free radicals - he hidden culprits: An update. Ind J Med Sci 1997; 51: 319-336.

3. Yasui $H$, Sakurai $H$. Age dependent generation of reactive oxygen species in the skin of live hairless rats exposed to UV light. Exp Dermatol 2003; 12: 655-661.

4. Boisnic S, Branchet-Gumila MC, Charpentier Le-Y, Segard C. Repair of UV-induced elastic fiber and collagen damage by $0.05 \%$ retinaldehyde 
cream in an ex- vivo human skin model. Dermatol 1999; 199: 43-48.

5. Gilchrest BA,Massachusetts MD. Skin aging and photoaging :an overview. J Am Acad Dematol 1989; 21: 610-613.

6. Rabe JH, Adam JM, Patrick JS, Warwick LM, Daniel $N$, Photoaging: mechanism and repair . J Am Acad Dermatol 2006; 55: 1-16.

7.Larnier C, Ortonne JP, Venot A, Faivre B, Beani JC, Thomas $P$, Brown $T C$, Sendagorta $E$. Evaluation of cutaneous photodamage using a photographic scale. Br J Dermatol 1994; 130: 167-173.

8.Torres ML ,Thiele JJ, Shindo Y, Han D, Packer L. Topical application of $\alpha$-tocopherol modulates the antioxidant network and diminishes ultraviolet- induced oxidative damage in murine skin. Br J Dermatol 1998; 138: 207215.

9. Kligman AM. Cosmeceuticals as a third category . Cosmet Toilet 1998; 113: 33-40.

10. Svobodova A, Psotova J, Walterova D. Natural phenolics in the prevention of UV -induced skin damage. A review. Biomed Papers 2003; 147: 137-145.

11. Gomez R, Goni FM, Macarulla JM. Carotenoids from marigold (Tagetes erecta) petals and their esterified fatty acids. Rev Esp Fisiol 1978; 34: 253-256.

12. Hadden WL, Watkins $R H$, Levy LW, Regalado E, Rivadeneira DM, Van Breemen RB, Schwartz SJ. Carotenoid composition of marigold (Tagetes erecta) flower extract used as nutritional supplement. J Agri Food Chem 1999 ; 47: 4189-4194.

13. Gregory GK, Chen TS, Philip T. Quantitative analysis of lutein esters in marigold flowers Tagetes erecta by high performance liquid chromatography. J Food Sci 1986 ; 51 :10931094.
14. Philip T, Berry JW. Nature of lutein acylation in marigold Tagetes erecta flowers. J Food Sci 1975; 40: 1089-1090.

15. Shinde NV, Kanase KG, Shilimkar VC, Undale VR, Bhosale AV. Antinociceptive and antiinflammatory effects of solvent extracts of Tagetes erectus Linn(Asteraceae) Trop $J$ Pharm Res. 2009; 8: 325-329.

16. Stahl $W$, Heinrich $U$, Jungmann $H$, Sies $H$, Tronnier $H$. Carotenoids and carotenoids plus vitamin $E$ protect against ultraviolet light -induced erythema in humans. Am J Clin Nutr 2000; 71: 795-798.

17. Ohkawa H, Ohishi N, Yagi K. Assay for lipid peroxides in animal tissues by thiobarbituric acid reaction. Anal Biochem 1979; 95: 351 358.

18. Ellman GL. Tissue sulfhydryl group. Arch Biochem Biophys 1959; 82: 70-77.

19. Sakuta T, Kanayama T. Marked improvement induced in photoaged skin of hairless mouse by ER36009, a novel RARY- specific retinoid ,but not by ER35794, an RXR -selective agonist. Int J Dermat 2006; 45: 1288-1295.

20. Kang S, Fisher GI, Voorhees JJ. Photoaging : pathogenesis ,prevention and treatment. Clin. Geriatr Med 2001; 17: 643-659.

21. Kligman LH. Manifestation, prevention and treatment . Dermatol Clin 1986; 4: 517-528.

22. Brenneisen $P$, Sies $H$,Scharffetter $K$. Ultraviolet-B irradiation and matrix metalloproteinase: From induction via signaling to initial events. Ann NY Acad Sci 2002; 973: 31-43.

23. Greul $A K$, Grundmann JU, Heinrich $F$, Pfitzner I,. Bernhardt J, Ambach A, Biesalski HK, Gollnick H..Photoprotection of UV-irradiated human skin : an antioxidant combination of vitamins $E$ and $C$, carotenoids, selenium and proanthocyanidines. Skin Pharmacol Appl Skin Physiol 2002; 15: 307315. 